health issues must extend their perspective beyond the bounds of policies and programmes if they are to help make a meaningful difference in the lives of those they serve.

This does not mean that policies and programmes are not needed - they clearly are. But the tendency to implement readymade models could easily miss the needs of the target groups. Community care programmes have to be tied to broader social and economic policies and programmes. Mental health professionals can contribute their expertise to this process and work in conjunction with these people and their families to strengthen their voices in the arena of human rights.

Brett, E. (1993) Voluntary agencies as developmental organisations: theorizing the problem of efficiency and accountability. Development and Change, 24, 269-303.

Jacob, K. S. (200I) Community care for mental disorders in developing countries. Problems and possible solutions. British Journal of Psychiatry, 178, 296-298.

Nyoni, S. (1987) Indigenous NGOs: liberation, selfreliance, and development. World Development, 15 (suppl.), 5I-56.

B. Saravanan Department of Psychiatry, Christian Medical College, Vellore - 632 002, India

\section{Mental health literacy in developing countries}

The article on mental health literacy by Jorm (2000) was interesting and stimulating and we were encouraged to see reference to the mental health literature in developing countries. However, it portrayed a rather incomplete and negative view of the situation. It has rightly been pointed out that the beliefs in supernatural causes of mental disorders are more widely held and traditional sources of help, such as spiritual healers, are preferred over medical advice for a range of mental health problems in these countries. It was not mentioned, however, that mental health literacy is perhaps part of general literacy. In some developing countries where more than half of the population may be illiterate the dimensions of mental health literacy are totally different from those in Western countries. One corollary of this is that mental health professionals will have to adopt innovative approaches to mental health literacy.

The community mental health programme in Pakistan is an example. With a literacy rate of about $40 \%$, it was not conceivable to adopt the approaches discussed by Jorm (2000). The innovative approaches adopted instead ranged from creating awareness at all levels of health personnel, including primary health care physicians, schoolchildren and teachers in the community, and collaborating with other sectors like traditional faith healers. One interesting attempt in this direction was to create awareness among schoolchildren and their teachers. We believe that the schoolchildren in rural areas are the eyes and ears of the community. In a study evaluating the effect of the school mental health programme it was shown that knowledge, attitudes and superstitions about mental health problems significantly improved in a group of schoolchildren, their friends and neighbours after implementation of the programme, compared with a control group (Rehman et al, 1998). More recently, the work has been extended to the detection of disabilities by children (Gater et al, 1999). This article, which gained the Barker Memorial Award, clearly showed the impact of improved mental health literacy through the strong messenger force of children in the rural community. An interesting impact of improved mental health literacy was its effect on general health indicators such as maternal mortality, infant mortality and the immunisation of children, which were significantly improved following integration of the mental health awareness campaign within primary health care (Maqsood et al, 2001). Similarly, educating the traditional faith healers assisted tremendously in identification and referral of people with mental illnesses for proper psychiatric treatment (Saeed et al, 2000). These are just a few examples of indigenous projects undertaken in the community, which highlight innovative approaches to mental health literacy in a developing country.

Recently, the issue of the role of the World Health Organization in improving mental health literacy in developing countries has been debated (Mubbashar \& Saeed, 2000) and directions for developing cost-effective and sustainable mental health programmes have been outlined.

Gater, R., Saeed, K., Mubbashar, M. H., et al (1999) Detection of disabilities by school children in rural Pakistan. Tropical Doctor, 29, 151-155.

Jorm, A. F. (2000) Mental health literacy. Public knowledge and beliefs about mental disorders. British Journal of Psychiatry, I77, 396-40I.

Maqsood, N., Saeed, K., Mubbashar, M. H., et al (200I) Impact of community based mental health programme on general health care. Lancet, in press.
Mubbashar, M. H. \& Saeed, K. (2000) Round table: setting the $\mathrm{WHO}$ agenda for mental health - WHO can help to combat mental health illiteracy. Bulletin of the World Health Organization, 78, 507-508.

Rehman, A., Mubbashar, M. H., Gater, R., et al (1998) Randomized trial of impact of school mental health programme in rural Rawalpindi, Pakistan. Lancet, 352, $1022-1025$.

Saeed, K., Gater, R., Hussain, A., et al (2000) The prevalence, classification and treatment of mental disorders among attendees of native faith healers in Rural Pakistan. Social Psychiatry and Psychiatric Epidemiology, 35, 480-485.

M. H. Mubbashar Rawalpindi General Hospital Rawalpindi, Pakistan

S. Farooq Postgraduate Medical Institute, Lady Reading Hospital, Peshawar, Pakistan

\section{Handedness and schizophrenia: genetic and environmental factors}

I would like to comment on the conclusions reached by Sommer et al (2001) in their meta-analysis of the literature on cerebral lateralisation and anatomical asymmetry in schizophrenia.

The article opens with the claim that: "Right-handedness, left cerebral dominance for language and normal cerebral asymmetry are considered to be secondary to a dominant allele, the 'right-shift factor" ". It must be kept in mind that this is only a hypothesis and has yet to be proven. Even if the centrality of this gene were demonstrated, the influence of environmental factors would still have to be accounted for. Otherwise, it would be impossible to explain the relatively common discordance for handedness in monozygotic twins: this discordance can only be due to disruption of the intrauterine neurodevelopment in one of the twins caused by the action of environmental factors. This is supported by Steinmetz et al (1995) in which magnetic resonance imaging of twins discordant for handedness showed that this discordance is mirrored by differences in brain lateralisation. Further confirmation of the importance of environmental factors in handedness comes from a Norwegian study by Salvesen et al (1993), in which a cohort of pregnant women were divided in two groups. Half of the mothers had real ultrasound scanning during pregnancy while the others had a sham investigation. When the children were examined after birth there was significant excess of left-handedness only in the group exposed to real ultrasonography. 